\title{
Study of the precipitation evolution in Catalonia using a mesoscale model (1971-2000)
}

\author{
A. Barrera-Escoda and J. Cunillera \\ Meteorological Service of Catalonia, Applied Research and Modelling Team, Department of the Environment and Housing, \\ Government of Catalonia, C. Berlín 38-48, 4a planta, 08029 Barcelona, Spain
}

Received: 15 December 2009 - Revised: 15 April 2010 - Accepted: 25 May 2010 - Published: 30 June 2010

\begin{abstract}
In this work the MM5 mesoscale model is used in order to analyse the temporal evolution of the precipitation for the period 1971-2000 in Catalonia (NE Iberian Peninsula). Three one-way nested domains with 135,45 and $15 \mathrm{~km}$ horizontal grid resolution and 23 vertical levels have been used. The simulation is performed nesting MM5 into the ERA40 reanalyses. Dynamical nudging is applied to the first domain. However, nudging is not applied in the second and third domains. In order to assess the performance of the developed methodology (main spatio-temporal precipitation characteristics), the results obtained in each simulation are compared with those obtained from ERA40 and observational data.

The results show a climatologically reliable distribution of the simulated precipitation spatial patterns for annual, semiannual, spring and summer precipitation compared to those obtained from 1100 rain gauges covering the whole study area. For winter and autumn the goodness of the results is much lower. Furthermore, the results for $15-\mathrm{km}$ outputs are better than the $45-\mathrm{km}$ ones. The simulations also reproduce well the evolution of annual anomalies for Catalonia and the probability density function (PDF) of monthly mean precipitation. They also improve the precipitation outputs from ERA40, which present an important negative trend and a drier PDF for the period 1971-2000. On the other hand, extreme values are not well reproduced by the simulation. Despite this fact, hydric extremes derived from extreme values (i.e. extreme rainy days and flood records) are well captured by the model.
\end{abstract}

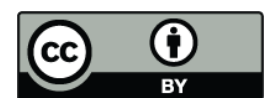

Correspondence to: A. Barrera-Escoda (tbarrera@meteo.cat)

\section{Introduction}

Global Circulation Models (GCM) do not have enough resolution $\left(1.8^{\circ}-3.5^{\circ}\right.$; Fowler et al., 2007) to reproduce the main climate characteristics at regional scale $\left(0.15^{\circ}-0.25^{\circ}\right.$; Salathé Jr et al., 2007). Therefore, they are not appropriate to study future regional or smaller scale impacts due to global warming during this century. In such way the use of downscaling techniques is advisable to cope with this problem (IPCC, 2007). There is a large number of downscaling techniques, which can be basically divided into two groups: statistical and dynamical. Statistical techniques use empirical relationships that relate large-scale climate variables (or predictors) to regional and local variables (or predictands). On the other hand, dynamical techniques use limited-area meteorological models (mesoscale models) to obtain the same variables. This is the one developed in the present work.

Unlike temperature, precipitation modelling by means of GCM presents great inaccuracies. They are more important in regions such as the Mediterranean zone, influenced by polar and tropical air masses. Many studies on precipitation modelling are just focused on winter and summer, while the other seasons are discarded from extensive and deeper analyses. However, spring and autumn are of extreme importance for the knowledge of hydric extremes and the management of water resources in the westerly leeward Mediterranean regions. This is the case of the studied area, Catalonia (northeast of Spain, see Fig. If for its location), where these seasons are the rainiest ones. Moreover, difficulties increase when floods and droughts are analysed because other factors under GCM resolution are involved: orography, mesoscale processes and anthropic factors as well. The studied area has a complex orography and river system. Mesoscale processes,

Published by Copernicus Publications on behalf of the European Geosciences Union. 

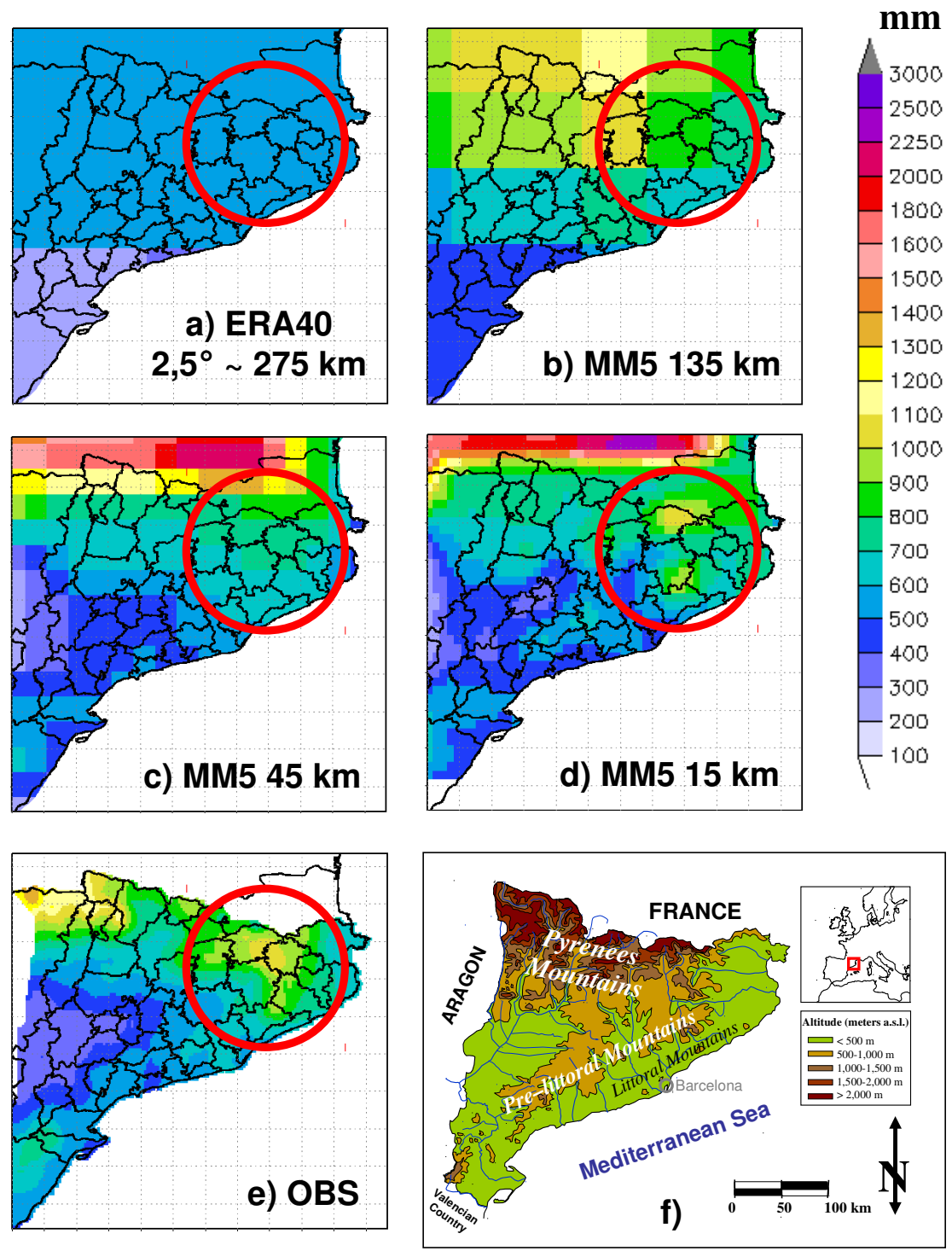

Fig. 1. Mean annual precipitation fields for the period 1971-2000 obtained by: ERA40 (a), MM5+ERA40 simulation for each integration domain (b-d) and $3 \mathrm{~km} \times 3 \mathrm{~km}$ observational grid (e) computed from 1100 pluviometric stations covering the whole studied area (AltavaOrtiz, 2010). The geographical location of the studied area is shown in (f).

such as orographic rainfalls or convective phenomena, have an important role in its climatology. Therefore, it is more evident the drawback of GCMs when its climate at regional scale is analysed.

In the present contribution, the MM5 mesoscale model has been used in order to develop a regionalised simulation of the present climate (1971-2000). The goal is to assess if the MM5 model is able to reproduce the main spatio-temporal characteristics of the climate in Catalonia (especially precipitation) and with the aim of developing future climate region- alised scenarios for Catalonia using the MM5 model nested into ECHAM5 GCM.

\section{Data}

Two kind of datasets have been used in the present study:

i) The European Centre for Medium-range Weather Forecast (ECMWF) 40-year reanalyses, called ERA40, with a $2.5^{\circ}$ spatial resolution (Uppala et al., 2005). These 
data are the initial and boundary conditions for the simulations. All the reanalyses are available every 6h (00:00, 06:00, 12:00 and 18:00 UTC). These data have been obtained from the ECMWF data server (http: //data-portal.ecmwf.int/data/d/era40_daily/).

ii) Observational monthly precipitation grid with a spatial resolution of $3 \mathrm{~km} \times 3 \mathrm{~km}$. This grid was computed from a maximum of 1100 rain gauges covering the whole study area (Altava-Ortiz, 2010). These data have allowed to validate the simulation.

\section{Methodology}

The MM5 mesoscale meteorological model (Grell et al., 1994; Dudhia et al., 2005) has been applied to perform a dynamical downscaling of the climate in Catalonia for the period 1971-2000. Three one-way nested domains with 135, 45 and $15 \mathrm{~km}$ horizontal resolution and 23 vertical levels have been defined to run the simulation. The first domain $\left(135 \mathrm{~km}\right.$, covering an area limited by $50^{\circ} \mathrm{W}$ to $50^{\circ} \mathrm{E}$ and $17^{\circ} \mathrm{N}$ to $58^{\circ} \mathrm{N}$ ) is centred on $0^{\circ} \mathrm{E}$ and $40^{\circ} \mathrm{N}$. The second domain $(45 \mathrm{~km})$ covers an area limited by $12^{\circ} \mathrm{W}$ to $8^{\circ} \mathrm{E}$ and $32^{\circ} \mathrm{N}$ to $47^{\circ} \mathrm{N}$ and the third domain $(15 \mathrm{~km})$ has an area limited by $1^{\circ} \mathrm{W}$ to $4^{\circ} \mathrm{E}$ and $40^{\circ} \mathrm{N}$ to $43^{\circ} \mathrm{N}$.

Dynamical nudging has been applied to the mother domain $(135 \mathrm{~km})$. This technique consists in forcing the simulation to follow boundary conditions from a global model during the whole integration. Consequently, mass continuity is guaranteed in simulations (limited area integration). This technique also allows to obtain consistent large-scale patterns with those presented in the global model (Salathé Jr et al., 2008). On the other hand, the second and third domains are integrated without dynamical nudging. Hence, the MM5 freely reproduces lower scale phenomena in these two domains and the used downscaling technique is really effective.

The whole process has been divided into 5-year simulations, reinitialised every five years. A simple set of physical parameterisations has been chosen. This is due to prior studies, as Fernández et al. (2007), conclude there is not any appropriate combination to define climate characteristics at regional scale for long simulations (5 years) in the Iberian Peninsula with the MM5 model. Therefore, parameterisations minimising the computing time are advisable. Thus, Grell algorithm (Grell, 1993; Grell et al., 1994) has been chosen for cumulus, simple ice parameterisation (Dudhia, 1989) for moisture, cloud scheme (Dudhia, 1989; Grell et al., 1994) for radiation, MRF scheme (Hong and Pan, 1996) for planetary boundary layer and finally a 5-layer soil model (Dudhia, 1996) for soil parameterisation.

\section{Results}

The ability of the simulation to reproduce the main spatiotemporal precipitation characteristics (spatial patterns, interannual variability, trends and PDFs) are verified by means of a comparison between simulated and observational values.

First of all, the mean annual precipitation fields for each integration domain, ERA40 reanalyses and observational data are shown in Fig. 1. The developed simulation produces a spatial pattern similar to observational one. The maximum values in the north and minima in the south-west and west areas are detected. However, the highest resolution integration is the only one which reproduces the maximum located in the north-east of Catalonia. The presence of this maximum is due to mesoscale factors, so that its detection by this simulation reinforces the ability of the downscaling method used. It is also important to comment that in general there is a high concordance between absolute observed and simulated values, but a slight general overestimation is observed with simulated values.

Referring to seasonal scale, a similar behaviour is presented (not shown). However, the concordance between model and observations is less robust for winter and autumn. Moreover, there is a general overestimation in the first half of the year and an underestimation in the other half. These two errors are annually compensated leading to a mean annual field very close to the observational one, as it can be seen in Fig. 1.

As regards temporal variability, Fig. 2 shows the evolution of mean annual precipitation anomalies obtained for the highest resolution domain with MM5, ERA40 and observations. This simulation presents a range of variability similar to the observational data. It is also important to stand out that in both simulation and observational data present a wet period at the beginning of the series and a dry period at the end. On the other hand, while an important decrease in ERA40 precipitation is detected, the observational precipitation does not have any statistically significant trend and the MM5 precipitation only presents a slight decrease (statistically significant) during the period 1971-2000. Significance of trends has been tested by a Monte Carlo technique (Livezey and Chen, 1983; Kunkel et al., 1999; Liebmann et al., 2004). In addition, the simulated values present a linear Pearson's correlation of 0.60 respects to observational data and ERA40 values present a lower correlation (0.54). Both correlations are statistically significant at a confidence level of $99 \%$. All of these facts give more evidences about the utility of the dynamical downscaling method used in this contribution.

Concerning to precipitation distribution, Fig. 3 shows the probability density functions (PDFs) of the mean monthly precipitation of ERA40, MM5 and observational data. The two last distributions are quite similar, but both PDFs are slightly different due to the overestimation in the mean annual simulated precipitation explained previously (Fig. 1). Therefore, a probability transfer towards the distribution tails 


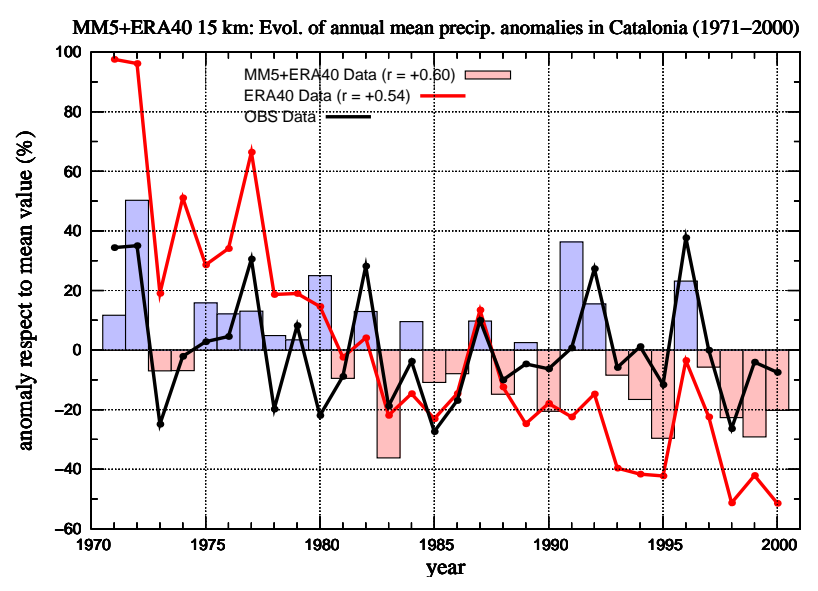

Fig. 2. Evolution of the mean annual anomalies of precipitation obtained by the regionalised simulation with MM5 at $15 \mathrm{~km}$ (MM5+ERA40, colour bars), ERA40 Reanalyses (red line) and observations (OBS, black line) for the period 1971-2000 in Catalonia. In parentheses, there are the linear Pearson's correlations between simulated and observational values.

is produced. This fact implies an increase in the probability of high precipitation values (PDF right tail) and a decrease in the frequency of simulated PDF central values (a lower peak) with respect to observed PDF. As it was illustrated in Fig. 2, an important difference exists between simulated and ERA40 data. This is ERA40 produces much lower monthly precipitation values than the MM5 simulation and observations. Consequently, the central values of ERA40 PDF present probability values higher than those presented in simulated and observational PDFs. This fact also corroborates the value of the downscaling technique used in this study.

Finally, regarding extreme precipitation (basically flood events), Fig. 4 has been built in order to compare the evolution of catastrophic floods (the most severe ones) in Catalonia (Barrera-Escoda, 2008) with a simulated variable derived from extreme precipitation. The absolute extreme precipitation values are not well captured by the simulation (not shown), as it could previously be known. The number of days with daily precipitation above $50 \mathrm{~mm}$ has been chosen as the variable to make the comparison with floods. This is a daily precipitation threshold related to floods in the studied area, since no flood was recorded in days with less than $50 \mathrm{~mm}$ in the last 150 years in Barcelona city (Barrera et al., 2006). Figure 4 shows a good coincidence between observed (flood evolution) and simulated (extreme precipitation events) values. The linear correlation between simulated values and observational data is 0.64 . There also exists a high frequency period of catastrophic floods at the beginning of the series which corresponds to a high frequency of extreme precipitation events in the simulation. On the other side, there is a low

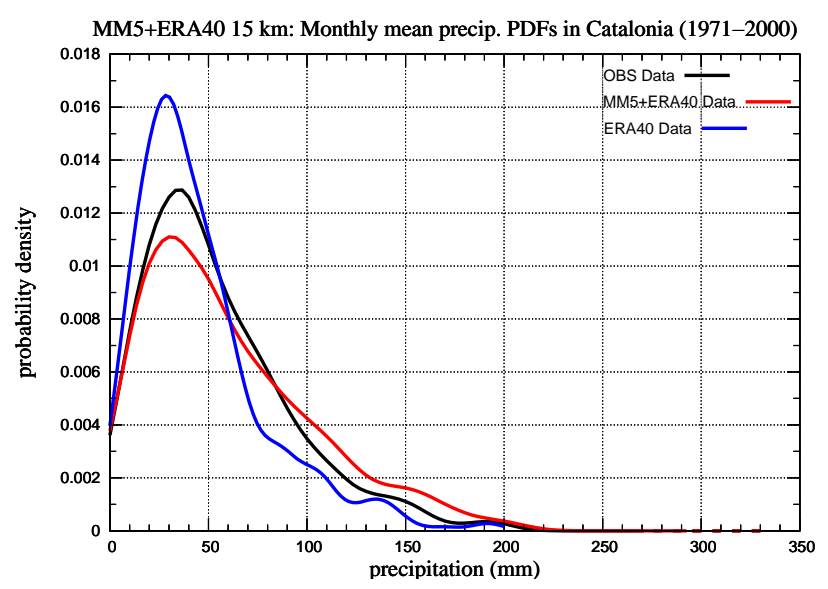

Fig. 3. Probability density functions (PDFs) for monthly mean precipitation obtained by the regionalised MM5 simulation at $15 \mathrm{~km}$ (MM5+ERA40, red line), the ERA40 Reanalyses (blue line) and observations (OBS, black line) for the period 1971-2000 in Catalonia.

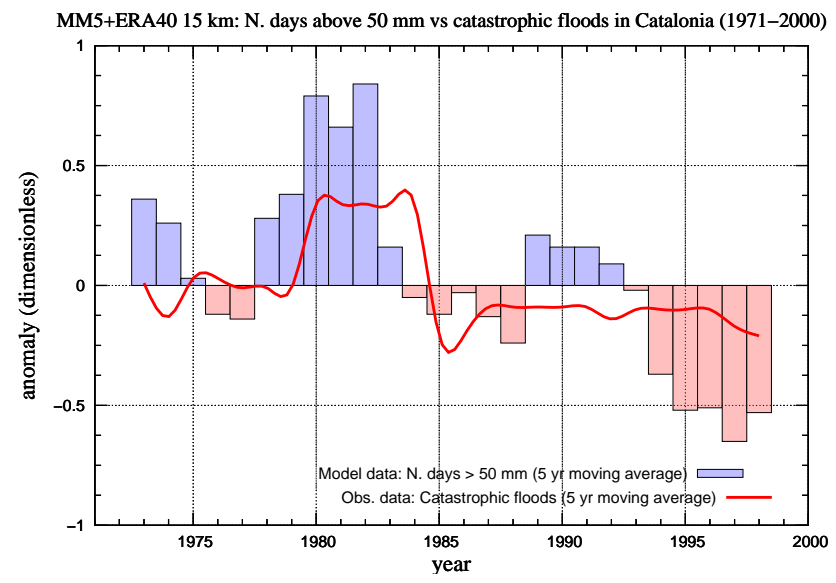

Fig. 4. Evolution of the number of days with daily precipitation above $50 \mathrm{~mm}$ obtained by the 15-km MM5 simulation (colour bars) and the catastrophic flood events in Catalonia (Barrera-Escoda, 2008) for the period 1971-2000. Data have been smoothed by a 5 -year moving average.

frequency period of flooding at the end of the series in coincidence with a low frequency period of extreme precipitation events in the simulation. This result confirms the ability of the developed method and the adequacy of the chosen variable to carry out the comparative study. 


\section{Conclusions}

The MM5 simulations nested into ERA40 reanalyses for the period 1971-2000 in Catalonia are able to reproduce the main spatio-temporal patterns of precipitation (spatial patterns, interannual variability, trends and PDFs) comparing with observations. However, they are not able to correctly reproduce the seasonal cycle. They present overestimated values from December to May and an underestimation from June to November. All in all, these differences are compensated at annual scale leading to absolute annual values similar to observational ones. The simulations also improve the precipitation outputs from ERA40 reanalyses, which present a significant decreasing annual precipitation trend and a too dry PDF for monthly mean precipitation during the period 1971-2000. These facts corroborate the ability of the developed technique.

To sum up, the obtained results allow to state the dynamical downscaling method, which has been presented here, is a good tool for climate regionalisation and it will be very useful to generate future regionalised scenarios from IPCC-AR4 GCM simulations. For example, one of the main results obtained by the simulations is the detection of the precipitation maximum located in the north-east of Catalonia. It is important to detect this maximum for future studies of water management in Barcelona metropolitan area. What is more, some other features must be improved to obtain better results, such as the seasonal cycle produced by the developed method.

Acknowledgements. The authors would like to thank Vicent AltavaOrtiz (University of Barcelona) for providing us the observational precipitation grid and Aitor Atencia and Montse Aran (Meteorological Service of Catalonia) for his help and advice during the development of the work. We also thank the assistance provided by the other members of Applied Research and Modelling Team from Meteorological Service of Catalonia.

Edited by: G. Boni

Reviewed by: one anonymous referee

\section{References}

Altava-Ortiz, V.: Caracterització i monitoratge de les sequeres a Catalunya i nord del País Valencià. Càlcul d'escenaris climàtics per al segle XXI (Characterising and monitoring droughts in Catalonia and Northern Valencian Country. Calculation of climatic scenarios for the 21st century), Ph.D. Thesis, Internal Publication, University of Barcelona, Barcelona, Spain, 2010.

Barrera, A., Llasat, M. C., and Barriendos, M.: Estimation of extreme flash flood evolution in Barcelona County from 1351 to 2005, Nat. Hazards Earth Syst. Sci., 6, 505-518, doi:10.5194/nhess-6-505-2006, 2006.
Barrera-Escoda, A.: Evolución de los extremos hídricos en Catalunya en los últimos 500 años y su modelización regional (Evolution of hydric extremes in Catalonia during the last 500 years and its regional modelling), Ph.D. Thesis, Internal Publication, University of Barcelona, Barcelona, Spain, http://www. zucaina.net/Publicaciones/Barrera-Escoda-TESIS-2008.pdf, 2008.

Dudhia, J.: Numerical study of convection observed during the winter monsoon experiment using a mesoscale two-dimensional model, J. Atmos. Sci., 46, 3077-3107, 1989.

Dudhia, J.: A multi-layer soil temperature model for MM5, in: Preprints, The Sixth PSU/NCAR Mesoscale Model Users Workshop (Boulder, Colorado, USA, 22-24 July 1996), 49-50, available online at: http://www.mmm.ucar.edu/mm5/mm5v2/ whatisnewinv2.html, 1996.

Dudhia, J., Gill, D., Manning, K., Wang, W., and Bruyere, C.: PSU/NCAR Mesoscale Modeling System Tutorial Class Notes and Users' Guide (MM5 Modeling System Version 3), Mesoscale and Microscale Meteorology Division, National Center for Atmospheric Research, Boulder, Colorado, USA, http: //www.mmm.ucar.edu/mm5/documents/tutorial-v3-notes.html, 2005.

Fernández, J., Montávez, J. P., Sáenz, J., González-Rouco, J. F., and Zorita, E.: Sensitivity of the MM5 mesoscale model to physical parameterizations for regional climate studies: Annual cycle, J. Geophys. Res.-Atmos., 112, D04101, doi:10.1029/ 2005JD006649, 2007.

Fowler, H. J., Blenkinsop, S., and Tebaldi, C.: Linking climate change modelling to impacts studies: recent advances in downscaling techniques for hydrological modelling, Int. J. Climatol., 27, 1547-1578, doi:10.1002/joc.1556, 2007.

Grell, G. A.: Prognostic evaluation of assumptions used by cumulus parameterizations, Mon. Weather Rev., 121, 764-787, 1993.

Grell, G. A., Dudhia, J., and Stauffer, D. R.: A description of the fifth-generation Penn State/NCAR Mesoscale Model (MM5), NCAR Technical Note 398, Mesoscale and Microscale Meteorology Division, 1994.

Hong, S. Y. and Pan, H. L.: Nonlocal boundary layer vertical diffusion in a medium-range forecast model, Mon. Weather Rev., 124, 2322-2339, 1996.

IPCC: Climate change 2007: the physical science basis; Contribution of Working Group I to the fourth Assessment Report of the Intergovenmental Panel on Climate Change, Cambridge University Press, UK and USA, http: //www.ipcc.ch/publications_and_data/publications_ipcc_fourth_ assessment_report_wg1_report_the_physical_science_basis.htm, 2007.

Kunkel, K. E., Andsager, K., and Easterling, D. R.: Long-term trends in extreme precipitation events over the conterminous United States and Canada, J. Climate, 12, 2515-2527, 1999.

Liebmann, B., Vera, C. S., Carvalho, L. M. V., Camilloni, I. A., Hoerling, M. P., Allured, D., Barros, V. R., Báez, J., and Bidegain, M.: An observed trend in central South American precipitation, J. Climate, 17, 4357-4367, doi:10.1175/3205.1, http: //journals.ametsoc.org/doi/pdf/10.1175/3205.1, 2004.

Livezey, R. E. and Chen, W. Y.: Statistical field significance and its determination by Monte Carlo techniques, Mon. Weather Rev., 111, 46-59, 1983. 
Salathé Jr, E. P., Mote, P. W., and Wiley, M. W.: Review of scenario selection and downscaling methods for the assessment of climate change impacts on hydrology in the United States pacific northwest, Int. J. Climatol., 27, 1611-1621, doi:10.1002/joc.1540, 2007.

Salathé Jr, E. P., Steed, R., Mass, C. F., and Zahn, P. H.: A high-resolution climate model for the US Pacific Northwest: Mesoscale feedbacks and local responses to climate change, J. Climate, 21, 5708-5726, doi:10.1175/2008JCLI2090.1, http: //journals.ametsoc.org/doi/pdf/10.1175/2008JCLI2090.1, 2008.
Uppala, S. M., Kållberg, P. W., Simmons, A. J., Andrae, U., da Costa Bechtold, V., Fiorino, M., Gibson, J. K., Haseler, J., Hernández, A., Kelly, G. A., Li, X., Onogi, K., Saarinen, S., Sokka, N., Allan, R. P., Andersson, E., Arpe, K., Balmaseda, M. A., Beljaars, A. C. M., van de Berg, L., Bidlot, J., Bormann, N., Caires, S., Chevallier, F., Dethof, A., Dragosavac, M., Fisher, M., Fuentes, M., Hagemann, S., Hólm, E., Hoskins, B. J., Isaksen, L., Janssen, P. A. E. M., Jenne, R., McNally, A. P., Mahfouf, J.-F., Morcrette, J.-J., Rayner, N. A., Saunders, R. W., Simon, P., Sterl, A., Trenberth, K. E., Untch, A., Vasiljevic, D., Viterbo, P., and Woollen, J.: The ERA-40 re-analysis, Q. J. Roy. Meteorol. Soc., 131, 2961-3012, doi:10.1256/qj.04.176, 2005. 